\title{
Compreendendo a Evasão em uma Década no Curso Sistemas de Informação à luz de fatores humanos e sociais
}

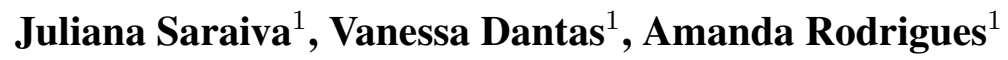 \\ ${ }^{1}$ Departamento de Ciências Exatas - Universidade Federal da Paraíba (UFPB) \\ Av. Santa Elisabete, s/n, Centro - Rio Tinto - PB - Brasil \\ \{julianajags, vanessa, amanda\}@dce.ufpb.br
}

\begin{abstract}
The high evasion rates demanded researches for understanding and mitigating the problems that lead to this phenomenon. Despite of the government programs trying to make education accessibility easier, such as REUNI, the enrollment cancellation rates are still growing, even in courses with high job opportunities, such as Information Systems (IS). Thus, this work investigated the evasion on human and social perspectives of a IS course at a federal university, implanted outside of the metropolitan context. A survey was applied with ex-students, obtaining 54 answers, which indicates that the lack of public and internal policies related to education fund support is one of the major evasion causes.
\end{abstract}

Resumo. Os altos índices de evasão na graduação vêm demandando pesquisas para tentar entender e mitigar os problemas que acarretam este fenômeno. Mesmo com programas de facilitação ao acesso à educação, como REUNI, a taxa de cancelamentos de matrículas ainda é crescente, inclusive em cursos que oferecem alta empregabilidade, a citar o curso de Sistemas de Informação (SI). Assim, este trabalho investigou a evasão sob a perspectiva de fatores humanos e sociais, no curso de SI de uma universidade federal, implantado fora do contexto metropolitano. Um survey foi aplicado com evadidos, obtendo-se 54 respostas, que indica a falta de políticas públicas e internas referentes a auxílios financeiros aos estudantes como uma das maiores causas de evasão.

\section{Introdução}

Apesar de pesquisas apontarem algumas possibilidades de melhorias nos cursos de graduação do Ensino Superior, a formação técnico-acadêmica ainda desponta como uma das principais ferramentas para se alcançar espaços no mercado de trabalho e nos programas de pós-graduação [Tomlinson 2012] [Manhães et al. 2012] [Garcia et al. 2017] [Silva Filho et al. 2007] [Digiampietri et al. 2016a]. Especificamente quando se observa o cenário de Tecnologia da Informação (TI), essa relação entre a qualidade técnica do egresso e a empregabilidade é ainda mais intensa, tendo em vista que este é um dos mercados mais aquecidos no Brasil e no mundo [UOL 2018] [Romer 2013] [Digiampietri et al. 2016b]. Neste cenário, encontra-se o curso de Bacharelado em Sistemas de Informação (BSI) que visa formar um profissional capaz de administrar o fluxo de informações que circulam dentro e fora de uma organização, através de redes de computadores [do Estudante 2018]. 
A despeito desta realidade, os indicadores de evasão nos cursos de graduação, especificamente nos cursos de TI, são cada vez mais alarmantes. Estudos apontam que os índices de evasão são altíssimos nos cursos de BSI e sugerem formas de reverter este cenário [da S. Junior and Vaz 2017] [Damasceno and Carneiro 2018] [Zanato et al. 2018] [Berardi and Bim 2017]. No entanto, apenas (ou majoritariamente) os fatores acadêmicos são analisados para tentar mitigar a evasão, enquanto fatores humanos e sociais podem ser mais significativos (ou tão importantes quanto) nessa tomada de decisão do aluno ao evadir do curso.

Isto posto, tendo em vista a alta taxa de evasão $(243 / 582-41,7 \%)$ dos alunos de BSI desta instituição nos seus 10 anos de implantação do curso, o problema de pesquisa aqui abordado é a falta de compreensão desse fenômeno sob a perspectiva da análise de fatores humanos e sociais, expressos através de seus perfis demográficos e razões de abandono do curso. Assim, o objetivo geral desse estudo é entender como a realidade e contextos locais de implantação no curso na região podem ter influenciado na alta taxa de cancelamento de matrículas nos 10 anos de sua existência. À vista disso, as seguintes Questões de Pesquisa (QP) foram elencadas: QP1 - Qual motivo de escolha do curso de BSI?; QP2 - Quais os principais motivos de cancelamento dos alunos?; QP3 - O que faria os alunos retomarem o curso de BSI?

Este artigo se organiza da seguinte forma, contando com esta seção já apresentada: a Seção 2 contém a metodologia utilizada, enquanto os resultados encontrados são discutidos na Seção 3. Em seguida, na Seção 4 são expostos alguns trabalhos relacionados a pesquisa, e por fim, algumas considerações finais são apresentadas na Seção 5.

\section{Metodologia}

Esta seção apresenta os passos metodológicos e explica como a coleta e análise de dados foram executadas. Para tentar atingir os objetivos, a ideia foi analisar três categorias de informação desses alunos: características demográficas, informações sobre a evasão dos discentes e formas que os fariam retornar ao curso. Acredita-se que com essa tríade de análise seja possível compreender como fatores humanos e sociais podem ter influenciado nesses cancelamentos de matrículas.

É importante lembrar que o cancelamento da matrícula pode ser efetuado pelo aluno, de forma expressa, ou pode ser feito pela Pró-Reitoria de Graduação da instituição, quando o aluno possui um elevado número de reprovações num mesmo componente curricular, ou quando a matrícula não é realizada pelo aluno em semestres consecutivos, caracterizando assim, respectivamente, jubilamento ou abandono do curso. Atualmente, a universidade onde a pesquisa ocorreu conta com um Sistema de Controle Acadêmico (SCA) que permite que todas as informações dos alunos sejam encontradas pelas coordenações dos cursos, a citar: naturalidade, gênero, origem escolar, disciplinas reprovadas, cancelamentos efetivados, notas dos alunos, CRA (Coeficiente de Rendimento Acadêmico), dentre outras.

Para coleta de dados um survey foi realizado através da aplicação de um questionário online enviado para todos os alunos que tiveram suas matrículas canceladas. Este questionário ficou disponível por 3 meses, com lembrete mensal para os que ainda não havia respondido. O questionário é composto pelos seguintes grupos de perguntas: (i) identificação discente (contato, ano que saiu do curso, raça), (ii) motivo pelo qual es- 
colheu o curso de BSI, (iii) motivo pelo qual evadiu-se do curso, (iv) dificuldades que o(a) levou a cancelar o curso, (v) possibilidades de retorno ao curso. Os dados advindos do survey foram tabulados em planilha eletrônica para serem posteriormente analisados e aplicada a codificação aberta preconizada pelo método da Teoria Fundamentada [Stol et al. 2016]. Esta codificação agrupa conceitos reconhecidos nos discursos dos participantes, baseando-se na terminologia utilizada por eles (evadidos). Esses conceitos auxiliam na compreensão do fenômeno ocorrido, que neste caso é a evasão do curso de BSI.

\section{Resultados}

\subsection{Perfil dos evadidos ao ingressar no curso}

Totalizando 243 alunos com matrículas canceladas nesses dez anos de existência do curso, 53 alunos responderam ao questionário online, tendo uma taxa de resposta de $21,8 \%$. No entanto, ressalta-se que os dados e a discussão não se torna irrelevante, tendo em vista a dificuldade de se coletar dados de alunos evadidos, que perderam o vínculo, e possivelmente, interesse no curso e na área. Além disso, esta é uma taxa aceitável inclusive em várias pesquisas no meio acadêmico.

Quanto à raça, dos 53 respondentes - 12 meninas e 41 meninos - a distribuição de autodeterminação foi a seguinte: 24 se consideraram brancos, 22 pardos, 5 negros e 1 ocorrência para caboclo e mulato cada. Quando questionados sobre o motivo pelo qual escolheram o curso (resposta à QP1), foram obtidas respostas variadas com 85 ocorrências, categorizadas em 7 grupos de motivos de ingresso no curso: (i) Curiosidade (2/85), (ii) Foi 2a ou 3a opção do SISU (8/85), (iii) Gostava de Ciências Exatas (6/85), (iv) Influência ou indicação de amigo/família (6/85), (v) Qualidade da instituição/curso (9/85), (vi) Sempre quis fazer (50/85), (vii) Outros (4/85) - Achei interessante, gostei da grade curricular, morava na cidade, bom mercado de trabalho. Em sua grande maioria, as respostas indicam que eles sempre quiseram fazer este curso ou sempre quiseram trabalhar com sistemas de computador $(58,8 \%)$, o que parece indicar que os mesmos realmente tinham interesse no curso a que se propuseram fazer. Ressalta-se que para esta pergunta, mais de um motivo poderia ser informado pelo evadido, por isso tem-se 53 respondentes e 85 motivos de ingresso elencados.

\subsection{Motivos de Evasão no curso de BSI}

Esta seção visa explanar os motivos das evasões dos alunos (resposta à QP2). A Tabela 1 mostra o tipo de cancelamento de matrícula que foi feito e a quantidade de cada um. Esclarece-se aqui que esses dados foram obtidos através do SCA, que emite relatório de evasão e retenção de todos os alunos ao longo dos anos.

É possível observar que, massivamente, o abandono do curso foi o maior motivo de evasão do curso de BSI nesses 10 anos. O abandono é caracterizado nessa instituição quando o aluno não faz a matrícula na época preconizada pela instituição em dois períodos seguidos ou não renova a matrícula após o período de trancamento total. Logo em seguida, vem o cancelamento feito de maneira explícita pelo próprio aluno, quando ele usa o SCA para indicar que não deseja mais fazer o curso.

Em terceiro lugar, mas com um número muito menos expressivo, quando comparado com os dois primeiros motivos apresentados, vem a transferência do aluno para 
Tabela 1. Motivos de Evasão

\begin{tabular}{|l|l|}
\hline TIPO CANCELAMENTO & QUANTIDADE \\
\hline Abandono & 152 \\
\hline Cancelamento pelo aluno & 54 \\
\hline Transferência para outra IES & 8 \\
\hline Cancelado pelo SISU & 7 \\
\hline Cadastro Cancelado & 5 \\
\hline Canc. Automático Proc. matrícula & 4 \\
\hline Reopção & 4 \\
\hline Reingresso no mesmo curso & 3 \\
\hline Prorrogação Administrativa & 3 \\
\hline Trancamento de Programa & 3 \\
\hline
\end{tabular}

outra Instituição de Ensino Superior. Isso indica que aqueles alunos que colocaram a opção no SISU para curso de BSI nesta instituição, possuíam realmente o interesse em cursá-lo. Este fato também pode ser observado nas respostas do survey que os alunos evadidos participaram, onde 45,6\% afirmam que o motivo de procurarem o curso foi sim porque sempre tiveram vontade de o fazer. Os outros motivos apresentados na Tabela 1 aparecem quase que de forma pontual, quando se leva em consideração o quantitativo dos motivos elencados.

Buscando entender essa alta ocorrência de abandono do curso e cancelamento feito pelo próprio aluno, por vontade própria, foi questionado aos evadidos (via survey) quais motivos levaram eles a isso. Foram listados 107 motivos apesar de 53 respondentes do questionário. Isso ocorreu porque os evadidos puderam escolher mais de um motivo que os levaram a abandonar o curso. Usando a técnica de codificação aberta da Teoria Fundamentada [Stol et al. 2016], um agrupamento de discursos dos alunos foi feito, chegando a 9 categorias de motivos, apresentados os quantitativos na Tabela 2. É possível observar na tabela 25 casos em que houve a (i) "Desistência do curso", onde os evadidos informaram que escolheram outro curso e que perderam o interesse por Sistemas de Informação (conforme trecho abaixo). Alguns inclusive já estavam formados à época desta pesquisa - evadidos mais antigos - em outras áreas. No entanto, as categorias que se sucedem podem dar indícios sobre o alto índice de abandono do curso e trazer à tona questões humanas e sociais que estão por trás desse cenário.

RESPONDENTE: ”...mudei de curso para Direito, em outra instituição."

As categorias (ii) "Deslocamento e Transporte"e "Estrutura do curso"possuem semelhante quantitativo (21/107). Na (ii) estão os motivos reportados pelos alunos sobre a logística de chegar na universidade tendo em vista que o campus não se encontra na capital do estado e muitos evadidos moram na capital ou em cidades circunvizinhas. As questões apontadas foram: disponibilidade de ônibus, horários de transporte limitados, dependência de transporte de prefeituras. Neste cenário, apesar de haver políticas públicas em parceria com a própria direção de centro e com a Pró-reitoria de Gestão Estudantil, esse ainda é um problema latente, que faz com que os alunos desistam do curso de BSI, conforme é possível identificar no discurso do evadido respondente:

RESPONDENTE: "Tive dificuldades financeiras para deslocamento e moradia"

No que tange ao item (iii) Estrutura do curso, enquadram-se aqui as questões de 
Tabela 2. Categorias de Motivos de Abandono do curso

\begin{tabular}{|l|l|}
\hline CATEGORIA CODIFICADA & QUANTITATIVO \\
\hline i) Desinteresse do curso & 25 \\
\hline ii) Deslocamento e Transporte & 21 \\
\hline iii) Estrutura do Curso & 21 \\
\hline iv) Dificuldades financeiras & 17 \\
\hline v) Dificuldades de aprendizagem & 13 \\
\hline vi) Adaptação Social & 4 \\
\hline vii) Mercado de Trabalho & 3 \\
\hline viii) Greve & 1 \\
\hline ix) Questões Pessoais & 1 \\
\hline
\end{tabular}

infraestruturas, como laboratórios e salas de aula, além dos horários de funcionamento do curso. Como o curso é integral, manhã e tarde, vários alunos se queixaram de não conseguirem conciliar com estágios, oportunidades de trabalho ou outras atividades oferecidas pela própria instituição, como pesquisa e extensão. Com este cenário, o NDE (Núcleo de Desenvolvimento Estruturante), a coordenação e as chefias de departamento que lidam com o oferecimento de turmas/disciplinas semestralmente, devem levar em consideração a possibilidade de ajustes de horários das disciplinas, para tentar fazer com que aumente a permanência desses alunos na instituição. Por outro lado, com relação às questões de infraestrutura, o processo de sucateamento e negligência das Instituições de Ensino em todo país, não só as de Ensino Superior, fazem com que os alunos se desmotivem e desistam do curso. No caso específico de BSI, foram reportados como problemas com relação a isso, a citar climatização das salas de aula, computadores obsoletos nos laboratórios e indisponibildade de recursos multimídia (datashow, caixa de som, TVs, etc). Diante desta evidência, ressalta-se a importância de repensar o processo de atualização e organização estrutural/infraestrutural do curso estudado.

Outro fator que levou os alunos a abandonarem o curso foram as (iv) dificuldades financeiras, aparecendo com 17 ocorrências. Nessa categoria, encontram-se os discursos relacionados com problema de deslocamento e moradia, além dos casos em que os alunos precisavam abandonar o curso para trabalhar e ajudar no sustento da família, a citar:

RESPONDENTE: ”Tive que desistir do curso pois precisei trabalhar para poder sustentar a família.”

RESPONDENTE: "Como morava em outra cidade, não consegui bolsas, residência ou auxílio para ajudar nas despezas, tive que desistir."

Neste cenário, vem à tona novamente a discussão sobre políticas públicas federais e universitárias para tentar suprir a carência econômica dos alunos. Entrar na universidade pública de qualidade já é uma árdua tarefa, porém, se manter no curso e terminar os estudos com qualidade é tão difícil quanto. Além das questões de aprendizagem, o dia a dia dos alunos que possuem dificuldades financeiras ou sociais fazem que com eles continuem à margem da sociedade, sem melhorar as oportunidades de vida, pois acabam desistindo da única alternativa de melhoria por questões financeiras, que sucumbem a possibilidade de progressão: a educação.

Apesar das questões humanas e sociais discutidas anteriormente, a (v) dificuldade de aprendizagem continua sendo elencada como motivo de evasão do curso. A despeito das tentativas de inserção das universidades nas cidades mais afastadas das capitais, como 
o Programa REUNI do Governo Federal, o Ensino Médio desses alunos precisa também ser observado e melhorado no país. A carga de déficit de conteúdo e habilidades de leitura e escrita faz com que disciplinas, até as mais simples, se transformem num pesadelo na vida dos alunos. Há casos em que os mesmos chegam a cursar 2 ou 3 vezes disciplinas introdutórias e por mais que se esforcem, não conseguem atingir e desenvolver as competências mínimas inerentes à disciplina, por vezes devido à déficit de conteúdos de matemática e português, como escrita e interpretação de textos. Neste cenário, há de se ressaltar casos em que os alunos fazem a prova do ENEM novamente para o mesmo curso, para tentar cursar as disciplinas que reprovaram, chegando a casos de 4 a 5 vezes de reprovações até conseguir passar. Eles precisam fazer um novo ENEM outra vez porque reprovações contínuas no mesmo componente curricular são causa de jubilamento nesta instituição.

RESPONDENTE: ”... sabemos que devido ao mal funcionamento do ensino básico no Brasil, os alunos chegam com grande dificuldade na Universidade em disciplinas como Português e Matemática..."

RESPONDENTE: ”... a principal disciplina do curso, sempre trancava quando acreditava que não passaria.”

Em menor quantidade, mas ainda existem, houve casos em que os alunos reportaram que se evadiram do curso por questões de Adaptações sociais (vi). Nessa categoria encontram-se os motivos de misoginia e sociabilidade, como é possível constatar nos enunciados abaixo:

RESPONDENTE: ”Dificuldades com colegas de apartamento.”

RESPONDENTE: ”...por muitas vezes pelo curso ter um maior público masculino, há uma maior dificuldade de entrosamento com as mulheres."

RESPONDENTE: "Infelizmente, a forma com que os professores tratavam as alunas como pessoas que iriam desistir cedo do curso e comentários que atribuíam falta de qualquer expertise na área por questão de gênero, era extremamente frustrante...”

RESPONDENTE: "... professores que não só ofendiam mulheres em geral como também o faziam especificamente para mulheres na área de Sistema, que me afastaram do curso.”

A falta de Mercado de Trabalho (vii) que absorva os alunos em graduação ou egressos é outro problema que faz com que os alunos evadam do curso. Algumas vezes, os estágios, que são todos disponibilizados na capital do estado, absorvem os alunos em graduação, que preferem transferir o curso, mesmo que para uma universidade privada ou de pior qualidade. Neste cenário, eles preferem conciliar com o estágio, que em breve pode vir a se tornar um emprego fixo. Em alguns casos inclusive, os alunos reportaram que passaram a cursar Sistemas de Informação na modalidade à distância para conciliar com as oportunidades de trabalho.

RESPONDENTE: ”Passei a trabalhar na capital e já cursava outra graduação na modalidade EaD.”

RESPONDENTE: ”Tive que trabalhar e na cidade do curso não tinha emprego."

RESPONDENTE: "Já tentei por duas vezes seguir o curso, porém, o horário dificulta diante do horário de trabalho... cheguei a fazer em uma instituição privada em na capital, só para conseguir conciliar."

As greves (viii) consecutivas (de alunos, funcionários e de professores) também afetaram o abandono, tendo em vista que a demora em ser chamado para o ingresso ou continuidade do curso pode ocasionar a desistência do mesmo. Acredita-se que alguns 
alunos passaram para outras universidades e desistiram de cursar BSI nesta instituição por causa dos atrasos no início do semestre letivo, ou mesmo começaram seus cursos em universidades particulares, na capital, e não tiveram mais interesse em se matricular em BSI. Isso é possível observar no discurso a seguir:

RESPONDENTE: "As greves que aconteceram no período foi o que gerou a desistência!"

Por fim, (ix) questões pessoais como mudança de endereço ou razões não expostas pelos respondentes foram apontadas. Ressalta-se que associado a este ponto pode haver influência da evasão quando se observa a distância entre o local do vínculo familiar dos evadidos com o endereço da instituição onde quase $67 \%$ dos respondentes moravam distante da universidade. Isso faz com que questões financeiras, de deslocamento, logística com a família, afeto e convivência familiar, que são tão importantes para o suporte dos alunos durante a graduação, se percam e não possam se concretizar. Ademais, desses 51,9\% dos alunos que moram entre 20 a $60 \mathrm{~km}$ de distância da universidade, estão aqueles que moram na capital do estado, onde há várias outras oportunidades de cursos e formação na área de TI, sendo muito mais tentador fazer um curso lá do que na região onde se encontra o curso hoje.

RESPONDENTE: "Sou da capital e consegui passar em uma universidade lá na região."

\subsection{Atrativos para retorno ao curso}

Tendo em vista que foram identificados fatores humanos e sociais que acarretaram a alta evasão dos alunos do curso de BSI desta instituição, viu-se a necessidade de investigar possibilidades de retorno ao curso. Esse questionamento tem por objetivo apresentar para a administração institucional direcionamentos que podem ser seguidos como políticas internas para diminuir a evasão no curso. A Figura 1 demonstra um quantitativo da possibilidade de retorno ao curso elencado pelos evadidos.

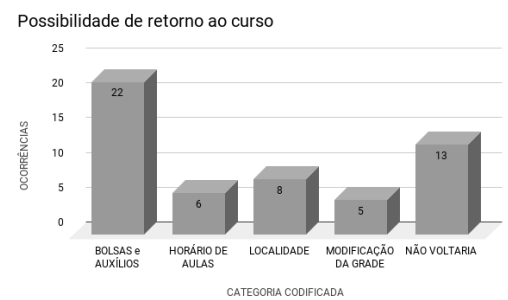

Figura 1. Atrativos para retorno ao curso.

É possível observar que a maioria (22/54) alega que bolsas e auxílios institucionais os manteriam na universidade e fariam com que eles retornassem ao curso. Vê-se aí claramente que fatores sociais e econômicos regeram a evasão desses alunos. Como consequência das dificuldades financeiras, as solicitações de mudança de horários de aula é um outro fator que poderia evitar a evasão, pois assim eles teriam como trabalhar ou estagiar e terem seu sustento. De forma semelhante, a questão do curso não ser na capital e na região não oferecer meios e oportunidades de absorver estes alunos, alguns disseram que fariam, e terminariam, o curso se fosse oferecido no campus da capital, como mostra o trecho a seguir:

RESPONDENTE: "Disponibilidade do curso no campus da capital ou flexibilidade no horário quanto as disciplinas, tendo em vista a necessidade de trabalhar para poder custear o curso dentre outras coisas.” 
A minoria deles ainda se queixa da grade curricular (5/54) e sugere modificações do PPC (Projeto Político Pedagógico) de curso ou em atividades complementares de ensino, como no discurso abaixo.

RESPONDENTE: "Penso que um acompanhamento em relação as disciplinas de Matemática e Programação ajudaria bastante (disciplinas extras, mais monitorias... talvez)."

Por fim, há uma parcela deles (13/54) que realmente não retornaria ao curso e se identificaram com outras áreas.

RESPONDENTE: "Como sou profissional de outra área hoje em dia não voltaria mais a fazer sistemas."

\section{Trabalhos Relacionados}

$\mathrm{Na}$ literatura, já existem vários trabalhos que visam retratar o problema de evasão nos cursos de graduação nas mais diferentes áreas buscando também propor soluções para tentar diminuir essa taxa. Dentre eles, é possível mencionar o trabalho de Zanatto et al. (2018) que, através do histórico escolar dos alunos evadidos e dos regularmente matriculados, conseguiram propor uma metodologia que prevê a situação dos alunos durante o curso [Zanato et al. 2018]. Sua proposta conseguiu auxiliar na tomada de ações para ajudar alunos em risco. Diferentemente do estudo citado, o presente trabalho não analisou os fatores acadêmicos e sim fatores humanos e sociais, que possam também ter influenciado na evasão do aluno, como questões financeiras, dificuldades prévias de aprendizagem, distância dos familiares, dentre outras.

Numa visão mais global, Soecki et al. (2018), analisaram a evasão no ensino superior durante o 1o semestre do curso [Soecki et al. 2018]. Como resultado da pesquisa, os autores puderam observar que as causas da evasão são os problemas financeiros e familiares, e o Ensino Médio de baixa qualidade. É importante ressaltar que a pesquisa aqui apresentada não foca apenas em analisar os motivos pelos quais os alunos evadiram apenas no primeiro semestre, mas em qualquer semestre durante os dez anos do curso.

Já Coutinho et al. (2018) propuseram um conjunto de métricas e técnicas de visualização de dados de evasão para dar suporte à tomada de decisão sobre este cenário [Coutinho et al. 2018]. Eles realizaram um estudo de caso com dois semestres de um curso de graduação e verificaram que foi possível comparar numericamente a evasão entre semestres, e com o suporte de visualização de dados foi possível identificar problemas mais facilmente e rapidamente. Todavia, as métricas e as técnicas propostas pelo trabalho citado não estão disponíveis para replicação do estudo. Dessa forma, novas medidas de correlação e variáveis para análise de médias e estatística descritiva foram definidas no presente trabalho para verificar o retrato da realidade da evasão nos dez anos de existência do curso de BSI, à luz de fatores humanos e sociais.

\section{Considerações Finais}

Este trabalho apresentou uma análise da evasão dos alunos no curso de BSI em 10 anos de implantação do mesmo, numa cidade um pouco afastada da região metropolitana da capital. Para isso, foram enviados 243 convites de questionário online para os alunos evadidos do curso, com o propósito de compreender os fatores humanos e sociais que levaram estes alunos a evadirem do curso. A análise de dados foi baseada no método de 
codificação aberta da Teoria Fundamentada. Foram identificadas 9 categorias de motivos pelos quais os alunos evadiram do curso, e apenas uma estava relacionada à estrutura do curso e dificuldades de aprendizagem. Majoritariamente, os problemas apontados como motivadores da evasão estão relacionados com as questões financeiras, distância da localização do curso com cidades que possuem boas oportunidades de estágio e trabalho, além da obrigatoriedade de estarem integralmente disponíveis ao curso (manhã e tarde) impossibilitando ou pelo menos dificultando atividades extra sala de aula.

Ademais, a distância entre o logradouro e a universidade influenciou na evasão, tendo em vista que a maioria dos respondentes moravam a mais de $50 \mathrm{~km}$ da universidade, acarretando problemas logísticos de transporte e deslocamento. Adaptações sociais e misoginia também foram relatadas pelos evadidos como causa de abandono/cancelamento do curso. À vista dos dados apresentados, é possível depreender que a maioria dos alunos que optam por cursar Sistemas de Informação nesta instituição sempre quiseram ter essa profissão. No entanto, questões financeiras e sociais, além da falta de mercado de trabalho local que absorva os alunos (em curso ou egresso) são os principais motivos pelos quais seja alto o índice de evasão. Neste sentido, o programa REUNI que se propôs a trazer educação de qualidade para locais afastados dos grandes centros urbanos não consegue atingir seu objetivo por completo tendo em vista a falta de políticas públicas no âmbito federal, com fomento de bolsas de estudos e subsídios estudantis (residência, alimentação para todos) e no âmbito local, com incentivos para desenvolvimento humano, social, estrutural, comercial e tecnológico do local.

Se a universidade é implantada distante da capital e não há políticas públicas em cooperação com universidade para absorver esse capital humano qualificado, eles são absorvidos em outros locais, com melhores oportunidades, onde possam receber um salário que subsidiem uma vida minimamente digna. Além disso, as programas de monitoria/tutoria, reformulações de PPC e observância do que é preconizado como melhores currículos de BSI não devem ser os únicos fatores levados em consideração para tentar diminuir evasão nesses cursos, tendo em vista que não são apenas aspectos acadêmicos que regem esse alto índice de evasão. Ademais, essa estruturação deve levar em consideração possibilidades de horários livres para os alunos construírem seus conhecimentos fora de sala de aula e não apenas seguir um modelo conteudista que não os fazem desenvolver soft skills adquiridos também em estágios, projetos de pesquisa, ensino e extensão.

Como trabalhos futuros, novas análises estatísticas de correlação entre dados contidos no SCA e os evadidos estão sendo feitas, a fim de extrair mais informações que retratem essa realidade sob diferentes perspectivas acadêmicas de rendimento escolar, dificuldades de aprendizagem e índices de reprovação. Complementarmente, pretende-se realizar uma análise de codificação axial da Teoria Fundamentada, a fim de correlacionar as categorias encontradas através das análises de discursos, tentando averiguar quais motivos de evasão são convergentes e como podem ser sanados ou minimizados simultaneamente.

\section{Referências}

Berardi, R. C. G. and Bim, S. A. (2017). A crise de identidade dos cursos de sistemas de informação é percebida "além-muros" das universidades no sul do brasil? iSys Revista Brasileira de Sistemas de Informação, 10(4):24-44. 
Coutinho, E., Bezerra, J., Bezerra, C. I. M., and Moreira, L. O. (2018). Uma análise da evasão em cursos de graduação apoiado por métricas e visualização de dados. In Simpósio Brasileiro de Informática Na Educação (SBIE’2018).

da S. Junior, L. R. and Vaz, N. A. P. (2017). Mineração de dados aplicada ao estudo da relação entre as reprovações nas disciplinas de lógica de programação e a evasão no curso de sistemas de informação. In Simpósio Unificados dos Cursos de Sistemas de Informação da UEG.

Damasceno, I. and Carneiro, M. (2018). Panorama da evasão no curso de sistemas de informação da universidade federal de uberlândia: Um estudo preliminar. In Simpósio Brasileiro de Informática Na Educação (SBIE'2018).

Digiampietri, L. A., Lauretto, M. S., and Nakano, F. (2016a). Estratégia de análise quantitativa para revisão de pré-requisitos em uma matriz curricular do curso de bacharelado em sistemas de informação. iSys - Revista Brasileira de Sistemas de Informação, 9(2).

Digiampietri, L. A., Nakano, F., and Lauretto, M. (2016b). Mineração de dados para identificação de alunos com alto risco de evasão: Um estudo de caso. Revista De Graduação USP, 1(1):17-23.

do Estudante, G. (2018). Sistemas de informação.

Garcia, L., Antunes, F., Lara, D., Riberio, C. P., and Miranda, C. C. (2017). Análise da evasão no ensino superior e suas motivações: Um estudo de caso em um curso de sistemas de informação. In Simpósio Brasileiro de Informática Na Educação (SBIE'2017).

Manhães, L. M. B., da Cruz, S. M. S., Costa, R. J. M., Zavaleta, J., and Zimbrão, G. Z. (2012). Identificação dos fatores que influenciam a evasão em cursos de graduação através de sistemas baseados em mineração de dados: Uma abordagem quantitativa. In Simpósio Brasileiro de Informática Na Educação (SBIE’2012).

Romer, R. (2013). Guia de cursos de ti: saiba qual é o mais indicado para você.

Silva Filho, R. L. L., Motejunas, P. R., Hipólito, O., and Lobo, M. B. C. M. (2007). A evasão no ensino superior brasileiro. Cadernos de Pesquisa da Fundação Carlos Chagas, 37(132):17-23.

Soecki, A. N., da Silva, A. Z., Sanches, S., Silva, H. N., de Almeida, A. P. F., de Souza, T. S. S., Agnoletto, E., and Rodrigues, R. C. (2018). Evasão no ensino superior. Revista Nativa, 7(1).

Stol, K., Ralph, P., and Fitzgerald, B. (2016). Grounded theory in software engineering research: A critical review and guidelines. In 2016 IEEE/ACM 38th International Conference on Software Engineering (ICSE), pages 120-131.

Tomlinson, M. (2012). Graduate employability: A review of conceptual and empirical themes. Higher Education Policy, 25(4):407-431.

UOL (2018). Os 10 cursos com maior empregabilidade.

Zanato, K. S., Ventura, T. M., and Riberio, J. M. (2018). Análise da evasão de alunos da área de tecnologia da informação por meio de um banco de dados orientado a grafos. Revista Eletrônica Argentina-Brasil de Tecnologias da Informação e da Comunicação, $1(8)$. 